Borneo Journal of Sciences \& Technology, 4(1): 18-25

DOI: http://doi.org/10.3570/bjost.2022.4.1-04

e-ISSN: 2672-7439

(C) 2018, UTS Publisher.

Submitted: 03 ${ }^{\text {rd }}$ October $2021 \quad$ Accepted: $05^{\text {th }}$ December $2021 \quad$ Published: $31^{\text {st } J a n u a r y ~} 2022$

\title{
Fretting Effect on the Fundamental Sound Frequency of Sape
}

\author{
${ }^{1}$ Tee Hao Wong, ${ }^{2}$ Ronald Yusri Batahong and ${ }^{3}$ Jedol Dayou \\ ${ }^{1}$ School of Foundation Studies, University of Technology Sarawak, 96000 Sibu, Sarawak, Malaysia \\ ${ }^{2}$ Department of Science, Technology, Engineering and Mathematics, Institut Pendidikan Guru \\ Kampus Kent, 89207, Tuaran, Sabah, Malaysia \\ ${ }^{3}$ Energy, Sound and Vibration Research Group (e-VIBS), Faculty of Science and Natural Resources, Universiti \\ Malaysia Sabah, 88400 Kota Kinabalu, Sabah, Malaysia
}

\begin{abstract}
Sape is one of the well-known string traditional musical instruments in Sarawak, Malaysia. It was normally played in a form of ritualistic music to induce trance but now gradually became a social instrument to accompany dances and for entertainment. Therefore, there is a growing interest in this instrument. Unfortunately, it cannot be found easily in the market. Among the possible reasons were proper guidelines that could be found in fabricating the instruments and therefore very few know how to make it. This paper presents a specific investigation on the effect of the fundamental frequency when the instrument is fretted. It was found that the fundamental frequency increased as the fret number increased. The fundamental frequency produced by each fret can be calculated using the formulated Fundamental Frequency (FF) equation and Gradient Harmonic Frequency (GHF) equation. On the other hand, the fretted string length is observed to be inversely proportional to the fundamental frequency production. The correlation is best represented by the power equation following the general equation $f_{0}=\alpha l_{n}^{-\beta}$. The correlation derived in this paper can be used as a guideline for a sape maker in the fabrication process. It is hoped that this study can generate more interest in the local traditional musical instruments to preserve the valuable local cultural heritage.
\end{abstract}

Keywords: Sape, traditional musical instrument, string instrument, fundamental frequency, cultural heritage.

\section{INTRODUCTION}

Much research has been carried out on musical instruments across the globe. One of the popular research interests is the study of the material used in musical instruments. The examples are the research on the effect of the material on the sound generation of string-type musical instruments [1-4]. They studied why certain woods are chosen in making musical instruments by understanding the physical properties of the woods and their effect on sound production. Paquier et al. [5] did similar research on the French bagpipe.

Another example of research was carried out by Yoshikawa and Waltham [3], Kusumaningtyas et al. [6], and Aditanoyo et al. [7] in which they study bamboo wood as the substitute material for the musical instrument like guitar and violin. To find an alternative wood which will comes cheaper and easier in a country like Indonesia. Bamboo has the potential to become the material used in making musical instruments.

Research on traditional musical instruments has also recently attracted the attention of researchers in Malaysia. In Peninsular Malaysia for example, Ismail et al. [8] studied the property and characteristics of the sound produced by kompang, a Malay traditional musical instrument. Computer music synthesis was used for the analysis of the sound produced. Kompang is noted as a pitch-less musical instrument and it is similar to other vibrating circular membrane instruments.

In Sabah, Batahong \& Dayou [9] carried out acoustics study on Kulintangan, a Sabah traditional musical instrument. This includes the fabrication process of the instrument, vibrational modes, and sound frequency produced by the instrument. Batahong et al. [10-12] also carried out a similar study on another type of Sabah traditional musical instrument which is sundatang. The research was carried out to understand the vibrational properties of the sundatang soundboard. The measurements were carried out by obtaining the FRF and modal parameters of the top plate and back plate of sundatang. The outcome of the research provides important information about the study of the quality development of sundatang.

Similarly, Ong \& Dayou [13] initiated the study on Sabah's traditional musical instrument which is sompoton. They studied the frequency spectrum produced by the sompoton and managed to compare the sound production by sompoton with an open-end pipe 
model. Further research on the sompoton was done by Wong et al. [14];[15] on the vibrator of the sompoton. Their study approach was based on the sound production of the vibrator of sompoton and analysed using a cantilever beam model. Different types of materials were used to facilitate the study. Sound data collected was then analysed to understand the fundamental frequency spectrum. Theoretical and experimental results were compared, and they managed to prove that the experimental result complied with the theoretical result with some deviation. A correction factor was then added to the theoretical formula.

Although there is some other research conducted on local musical instruments, no known publication on Sarawak local musical instruments despite being blessed with diverse local musical arts and musical instruments from different ethnicities. Sape or sapeh is one of the most popular traditional musical instruments among local residents. It is a string-type instrument and has a shape similar to a guitar. It is carved from a single bole of softwood, usually the meranti and merdang. The elongated body is hollowed out and functions as a resonator. The strings were made from the sago tree originally, but now these have been replaced by nylon or steel strings. The common sape usually has three or four strings. Figure 1 and Figure 2 show the schematic drawing and the actual photo of a sape.

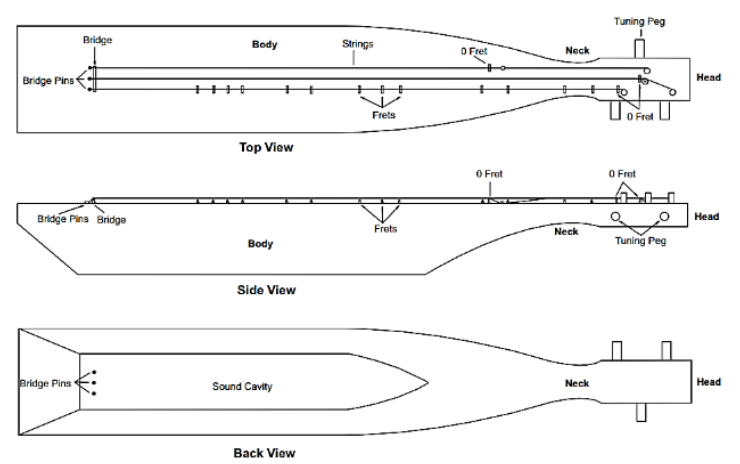

Figure 1: Schematic Drawing of sape

To better understand the musical instrument, vibrational and acoustical properties of the instrument are the foundation. It is very important to understand the sound and vibration production and the sound radiation of the instrument. For the sape, the sound or vibration is generated by plucking the string, the vibration is then transferred to the bridge and then to the body of the sape. It is then radiated to the surrounding from the hollowed body at the back of the instrument.

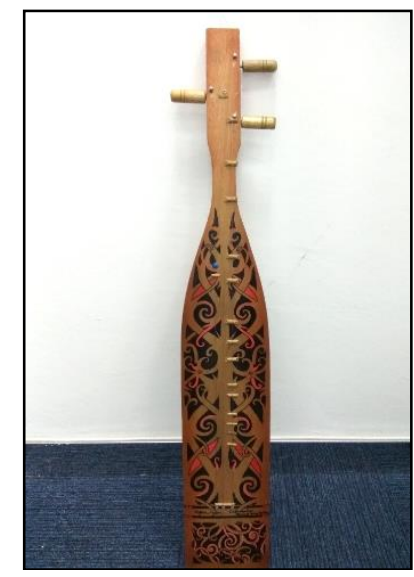

Figure 2: Traditional Musical Instrument, sape.

In this paper, the study is focused on the effect of fretting on the sound frequency produced by the sape. There are thirteen frets (refer to Figure 1) fitted under the first string of the instrument. The distance of each fret from the bridge does not follow any arithmetic sequences. This is because there is no fabrication guideline on fitting the frets of the sape. The installation of the frets is solely dependent on the technique and experience of the makers. Hence, this study serves as a starting point for exploring the musical instrument as a whole.

\section{MATERIALS AND METHODS}

In this study, a three strings sape made from merdang wood was used. Merdang is the most popular material used by sape makers. The sape was made by Mr. Mathew Ngau Jau, a well-known sape maker from Bau, Kuching, Sarawak, Malaysia.

The measurement in this study was conducted in the Physics Laboratory in UTS where the background noise is around $32 \mathrm{~dB}$ when no activity in the lab. Relatively high sensitivity $(-37 \mathrm{~dB})$ and flat audio frequency response Audio-Technica AT2020 microphone, connected to Intel ${ }^{\circledR}$ High Definition sound card were used for the audio recording with the help of Audacity software. The sound produced by the sape was recorded at a $44.1 \mathrm{kHz}$ sampling rate.

To study the effect of fretting the instrument, the first string was used as the other string has no fret (see Figure 3(a)). The sape was placed in the same absolute position for each measurement. The AT2020 microphone was positioned $10 \mathrm{~cm}$ above the strings of the sape as shown in Figure 4. For the respective fret, a finger, located above the fret number of interest (see Figure 3(a)) was pressed down until the string firmly touched the tip of the fret as shown in Figure 4(b). In this condition, the string was being fretted with the respective fret number. 
The position where the string is plucked is not fixed as the sound sample collections are done on all the frets in which reduced the string length between the fret and the bridge. The usual plucking position is somewhere one-third of the sting length measured from the bridge. Since the plucking position, angle and force will affect the decay rate, resonances $[16,17]$, the string is plucked with a relatively similar amplitude of $5 \mathrm{~mm}$ from its equilibrium position (plucking the string to the side right of the sape body will make the same amplitude of sound provided that the plucking amplitude is the same).

The plucking of the sape string was repeated five times for each fret. All recorded sound was analysed using Matlab to get its FFT where Matlab FFT default size was used to determine the frequency of the sound from sape.

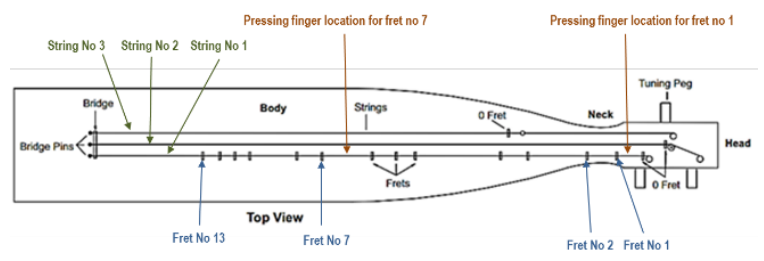

(a) Detail anatomy of sape

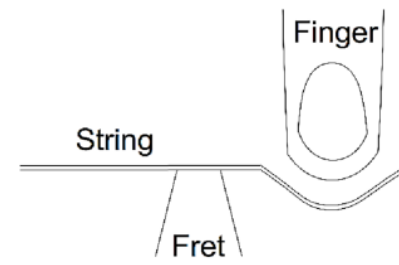

(b) Peninsular fretting method for the string

Figure 3: Detail anatomy of the sape and the fretting method of the string

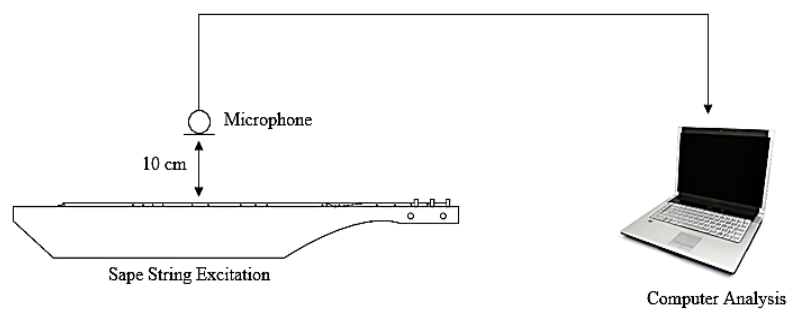

Figure 4: Experiment setup of the sound recording and data analysis

\section{RESULTS AND DISCUSSION}

\section{A. Effects of Fret Numbers on Fundamental Frequency}

In this study, it is presumed that the fundamental frequency will increase as the fret number increases. This is based on the fact that as the fret number increases, the measured string length from the bridge to the fret will decrease. Hence, it leads to higher frequency produced because the frequency is inversely proportional to the string length.

The sound samples for every fret were recorded using Audacity and then analysed using MATLAB to get the frequency spectrum. The spectrogram shows a graph of intensity against frequency. The interest of this study is mainly focused on the harmonics contents of the sound produced for each plucking. Hence, the harmonic frequencies, peak values, or intensities of the harmonic frequency were obtained for further analysis.

A total of 65 sound samples generated from the first string at different frets were recorded and analysed. The averaged results for five measurements of each fret are presented in Table 1. It can be seen that the fundamental frequency of the strings increases as the fret number increases. The results of the fundamental frequency as a function of the fret number are also shown in the plotted exponential graph in Figure 5 which can be written in an equation as

$$
f_{0}=151.11 e^{0.1398 n}
$$

where is the fundamental frequency and $\mathrm{n}$ is the fret number.

Table 1: Frequency analysis of sound from the $1^{\text {st }}$ string at different frets of the sape

\begin{tabular}{ccccc}
\hline \multirow{2}{*}{ Harmonics } & \multicolumn{2}{c}{ F1 } & \multicolumn{2}{c}{ F2 } \\
\cline { 2 - 5 } & $\begin{array}{c}\text { Freq } \\
(\mathbf{H z})\end{array}$ & Ratio & $\begin{array}{c}\text { Freq } \\
(\mathbf{H z})\end{array}$ & Ratio \\
\hline 1 & 175.18 & 1.00 & 194.26 & 1.00 \\
2 & 350.72 & 2.00 & 387.36 & 1.99 \\
3 & 526.54 & 3.01 & 581.50 & 2.99 \\
4 & 701.08 & 4.00 & 775.94 & 3.99 \\
5 & 879.14 & 5.02 & 971.72 & 5.00 \\
6 & 1054.00 & 6.02 & 1166.80 & 6.01 \\
7 & 1230.20 & 7.02 & 1363.60 & 7.02 \\
8 & 1407.40 & 8.03 & 1558.60 & 8.02 \\
9 & 1587.20 & 9.06 & 1756.80 & 9.04 \\
10 & 1761.20 & 10.05 & 1948.20 & 10.03 \\
11 & 1943.40 & 11.09 & 2148.60 & 11.06 \\
\hline
\end{tabular}

(a) $1^{\text {st }}$ fret $(\mathrm{F} 1) \& 2^{\text {nd }}$ fret $(\mathrm{F} 2)$ 
Fretting Effect on The Fundamental Sound Frequency of Sape

\begin{tabular}{ccccc}
\hline \multirow{2}{*}{ Harmonics } & \multicolumn{2}{c}{ F3 } & \multicolumn{2}{c}{ F4 } \\
\cline { 2 - 5 } & $\begin{array}{c}\text { Freq } \\
\mathbf{( H z )}\end{array}$ & Ratio & $\begin{array}{c}\text { Freq } \\
\mathbf{( H z )}\end{array}$ & Ratio \\
\hline 1 & 234.52 & 1.00 & 257.26 & 1.00 \\
2 & 468.22 & 2.00 & 514.54 & 2.00 \\
3 & 703.46 & 3.00 & 773.54 & 3.01 \\
4 & 940.06 & 4.01 & 1035.00 & 4.02 \\
5 & 1176.60 & 5.02 & 1293.60 & 5.03 \\
6 & 1415.60 & 6.04 & 1553.20 & 6.04 \\
7 & 1654.00 & 7.05 & 1815.80 & 7.06 \\
8 & 1884.80 & 8.04 & 2076.80 & 8.07 \\
9 & 2126.40 & 9.07 & 2342.20 & 9.10 \\
10 & 2370.60 & 10.11 & 2607.00 & 10.13 \\
11 & 2609.80 & 11.13 & 2896.20 & 11.26 \\
\hline
\end{tabular}

(b) $3^{\text {rd }}$ fret $(\mathrm{F} 3) \& 4^{\text {th }}$ fret $(\mathrm{F} 4)$

\begin{tabular}{ccccc}
\hline \multirow{2}{*}{ Harmonics } & \multicolumn{2}{c}{ F5 } & \multicolumn{2}{c}{ F6 } \\
\cline { 2 - 5 } & $\begin{array}{c}\text { Freq } \\
\mathbf{( H z )}\end{array}$ & Ratio & $\begin{array}{c}\text { Freq } \\
\mathbf{( H z )}\end{array}$ & Ratio \\
\hline 1 & 315.72 & 1.00 & 349.82 & 1.00 \\
2 & 628.76 & 1.99 & 699.54 & 2.00 \\
3 & 950.80 & 3.01 & 1053.20 & 3.01 \\
4 & 1268.60 & 4.02 & 1405.80 & 4.02 \\
5 & 1588.00 & 5.03 & 1762.00 & 5.04 \\
6 & 1903.60 & 6.03 & 2119.00 & 6.06 \\
7 & 2230.20 & 7.06 & 2477.60 & 7.08 \\
8 & 2552.60 & 8.09 & 2829.60 & 8.09 \\
9 & 2877.20 & 9.11 & 3201.20 & 9.15 \\
10 & 3204.40 & 10.15 & 3566.60 & 10.20 \\
11 & 3409.80 & 10.80 & 3935.40 & 11.25 \\
\hline
\end{tabular}

(c) $5^{\text {th }}$ fret $(\mathrm{F} 5) \& 6^{\text {th }}$ fret $(\mathrm{F} 6)$

\begin{tabular}{ccccc}
\hline \multirow{2}{*}{ Harmonics } & \multicolumn{3}{c}{ F7 } & \multicolumn{2}{c}{ F8 } \\
\cline { 2 - 5 } & $\begin{array}{c}\text { Freq } \\
\mathbf{( H z )}\end{array}$ & Ratio & $\begin{array}{c}\text { Freq } \\
\mathbf{( H z )}\end{array}$ & Ratio \\
\hline 1 & 393.26 & 1.00 & 393.26 & 1.00 \\
2 & 786.78 & 2.00 & 786.78 & 2.00 \\
3 & 1181.40 & 3.00 & 1181.40 & 3.00 \\
4 & 1579.20 & 4.02 & 1579.20 & 4.02 \\
5 & 1976.00 & 5.02 & 1976.00 & 5.02 \\
6 & 2378.20 & 6.05 & 2378.20 & 6.05 \\
7 & 2780.00 & 7.07 & 2780.00 & 7.07 \\
8 & 3184.00 & 8.10 & 3184.00 & 8.10 \\
9 & 3596.40 & 9.15 & 3596.40 & 9.15 \\
10 & 3963.60 & 10.08 & 3963.60 & 10.08 \\
11 & 4367.60 & 11.11 & 4367.60 & 11.11 \\
\hline
\end{tabular}

(d) $7^{\text {th }}$ fret $(\mathrm{F} 7) \& 8^{\text {th }}$ fret $(\mathrm{F} 8)$

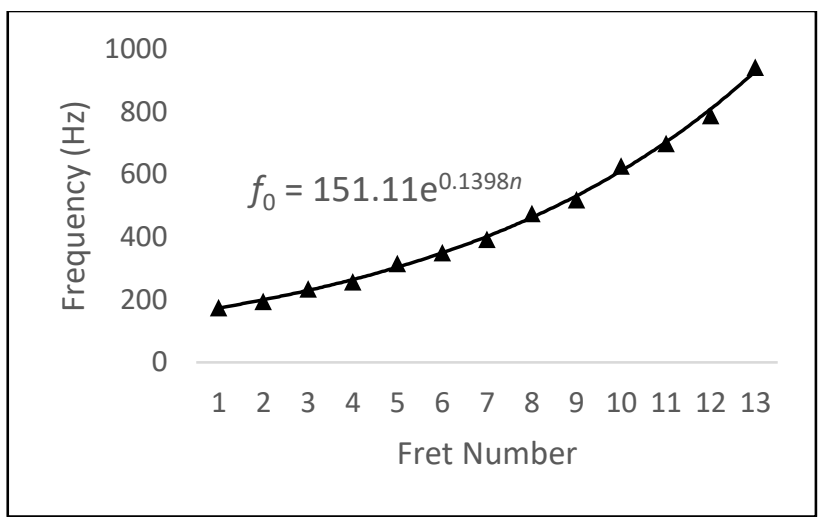

Figure 5: Fundamental frequency against fret number of the 1 st string of sape

The sounds produced by the string are in harmonics where the "Harmonics 1" is the fundamental frequency, and the consequence numbers are called the harmonics. The harmonics can be proven by using the ratio analysis in Equation (2)

$$
\text { ratio }=\frac{f_{i}}{f_{0}}
$$

where $f_{0}$ is the fundamental frequency or first harmonic and $f_{i}$ is the consequence frequencies or harmonics, where $i=1,2,3,4,5, \ldots n$. The geometric sequence of the ratio of the fundamental frequency to the consequences frequencies can be listed as $f_{0}, 2 f_{0}, 3 f_{0}, \ldots n f_{0}$.

As previously mentioned, the string of interest has a total of 13 frets and the fundamental frequency and harmonics of each fret produced are plotted in Figure 6. For every fret, a total of 11 harmonics frequencies have been taken from the FFT analysis. From the figure, each fret produces a linear function. The equation of the linear functions is tabulated in Table 2.

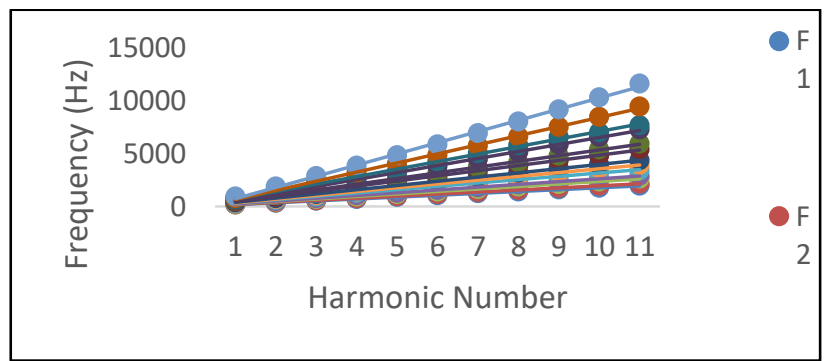

Figure 6: Harmonics frequencies of the sape, when the 1st string was plucked at different frets (F1 - Fret no 1; F2 - Fret no 2; ...; F13 - Fret no 13). 
Table 2: Harmonic equations of sound when the 1st string was plucked at different frets.

\begin{tabular}{ll}
\hline Fret Number & Harmonic Equation \\
\hline$F 1$ & $f=176.62 n-3.7418$ \\
$F 2$ & $f=195.44 n-4.1378$ \\
$F 3$ & $f=237.47 n-8.0829$ \\
$F 4$ & $f=262.51 n-14.605$ \\
$F 5$ & $f=316.02 n+6.5695$ \\
$F 6$ & $f=358.21 n-22.022$ \\
$F 7$ & $f=398.52 n-10.555$ \\
$F 8$ & $f=488.57 n-35.059$ \\
$F 9$ & $f=540.28 n-58.404$ \\
$F 10$ & $f=662.65 n-101.69$ \\
$F 11$ & $f=712.40 n-28.52$ \\
$F 12$ & $f=862.62 n-205.05$ \\
$F 13$ & $f=1059.5 n-329.12$ \\
\hline
\end{tabular}

Based on the observation of linear functions in Table 2, the value of the gradient increases as the fret number increased. It is also found that the gradient of the linear function of each fret is close to its fundamental frequency. The gradient of the linear function for each fret is calculated and shown in Table 3. It can be seen that the gradient increases as the fret number increased.

Table 3: The gradient value (frequency against fret number) of each fret and the fundamental frequency for the 1 st string of sape

\begin{tabular}{cccc}
\hline Fret & Gradient, $\mathbf{m}(\mathbf{H z})$ & $\boldsymbol{f}_{\boldsymbol{0}},(\mathbf{H z})$ & $\boldsymbol{m} \boldsymbol{-} \boldsymbol{f}_{\boldsymbol{o}, \boldsymbol{( H z}}$ \\
\hline F1 & 176.62 & 175.18 & 1.44 \\
F2 & 195.44 & 194.26 & 1.18 \\
F3 & 237.47 & 234.52 & 2.95 \\
F4 & 262.51 & 257.26 & 5.25 \\
F5 & 316.02 & 315.72 & 0.30 \\
F6 & 358.21 & 349.82 & 8.39 \\
F7 & 398.52 & 393.26 & 5.26 \\
F8 & 488.57 & 475.30 & 13.27 \\
F9 & 540.28 & 519.42 & 20.86 \\
F10 & 662.65 & 626.62 & 36.03 \\
F11 & 712.40 & 698.52 & 13.88 \\
F12 & 862.62 & 788.48 & 74.14 \\
F13 & 1059.50 & 942.44 & 117.06 \\
\hline
\end{tabular}

The gradient value of all the linear functions in Figure 6 was then plotted versus the fret number as shown in Figure 7 which gives an exponential curve. Mathematically, the curve can be written in an equation given by

$$
m=148.69 e^{0.1469 n}
$$

According to Batahong \& Dayou (2016), Equation (1) is named as Fundamental Frequency (FF) equation, and Equation (3) is named as Gradient Harmonic Frequency (GHF) equation of fretted string of sape. Comparing Equation (1) and Equation (3), it can be concluded that both equations are similar in which $m \approx f_{0}$. Hence, Equation (3) can be rewritten as

$$
f_{0}=148.69 e^{0.1469 n}
$$

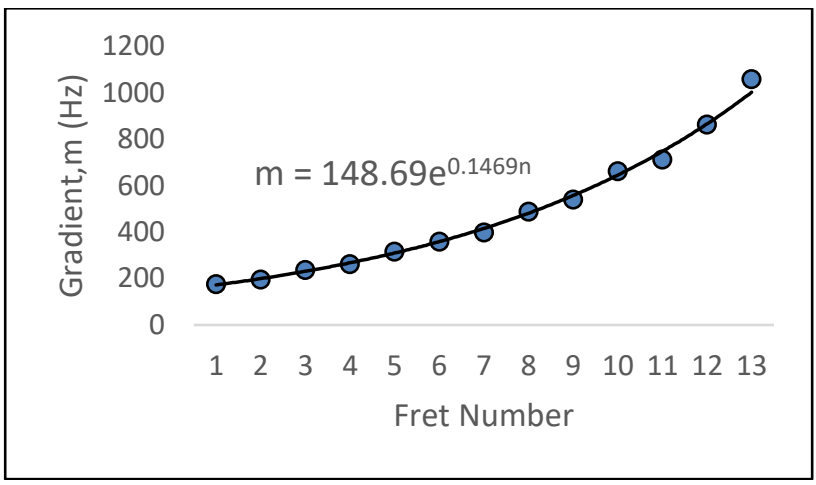

Figure 7: Gradient of each fret's harmonic frequency against fret number.

Table 4 shows the comparison between the FF equation and GHF equation in predicting the measured fundamental frequency. The comparison is done by applying Student's T-tests to see if there's any significant difference between both equations. The null hypothesis was set as there is no significant difference between both equations. Results from the T-test proved that the null hypothesis set is true in which the P-value obtained is more than 0.05 . This explained that both FF and GHF equations can be used to predict the fundamental frequency produced by the sape.

Table 4: Comparison of recorded and calculated 1st string's fundamental frequency at each fret.

\begin{tabular}{cccc}
\hline Fret & $\begin{array}{c}\text { Measured } \\
(\mathbf{H z})\end{array}$ & $\begin{array}{c}\text { Calculated } \\
(\mathbf{H z})\end{array}$ & $\begin{array}{c}\text { Absolute } \\
\text { Difference } \\
(\mathbf{H z})\end{array}$ \\
\hline 1 & 175.18 & 173.78 & 1.40 \\
2 & 194.26 & 199.86 & 5.60 \\
3 & 234.52 & 229.85 & 4.67 \\
4 & 257.26 & 264.33 & 7.07 \\
5 & 315.72 & 303.99 & 11.73 \\
6 & 349.82 & 349.61 & 0.21 \\
7 & 393.26 & 402.06 & 8.80 \\
8 & 475.30 & 462.39 & 12.91 \\
9 & 519.42 & 531.77 & 12.35 \\
10 & 626.62 & 611.56 & 15.06 \\
11 & 698.52 & 703.32 & 4.80 \\
12 & 788.48 & 808.85 & 20.37 \\
13 & 942.44 & 930.21 & 12.23 \\
\hline
\end{tabular}

(a) FF equation 


\begin{tabular}{cccc}
\hline Fret & $\begin{array}{c}\text { Measured } \\
(\mathbf{H z})\end{array}$ & $\begin{array}{c}\text { Calculated } \\
(\mathbf{H z})\end{array}$ & $\begin{array}{c}\text { Absolute } \\
\text { Difference }(\mathbf{H z})\end{array}$ \\
\hline 1 & 175.18 & 172.22 & 2.96 \\
2 & 194.26 & 199.47 & 5.21 \\
3 & 234.52 & 231.03 & 3.49 \\
4 & 257.26 & 267.59 & 10.33 \\
5 & 315.72 & 309.94 & 5.78 \\
6 & 349.82 & 358.98 & 9.16 \\
7 & 393.26 & 415.78 & 22.52 \\
8 & 475.30 & 481.58 & 6.28 \\
9 & 519.42 & 557.78 & 38.36 \\
10 & 626.62 & 646.04 & 19.42 \\
11 & 698.52 & 748.27 & 49.75 \\
12 & 788.48 & 866.67 & 78.19 \\
13 & 942.44 & 1003.82 & 61.38 \\
\hline
\end{tabular}

(b) GHF equation

\section{B. Effects of Fret Position on Fundamental Frequency}

Another research approach done in this study is to understand the effects of the frets installation positions of the sape on the fundamental frequency produced. There is a total of 13 frets installed for the 1st string. As the fret number increases from 0 frets, the fretted string length will decrease. It is known that the relationship of the frequency produced and the fretted string length is inversely proportional to one another. However, the main objective of the study is to obtain the relationship equation between the frequency and the fret distance from the bridge of the instrument. As mentioned earlier in this paper, the installation of the frets on this instrument follows no standard method. Hence, the results of this study can provide a guideline for the future fabrication method.

Taking the result of fundamental frequencies from Table 1 to compare with the measured distance of the frets from the bridge, the results are presented in Table 5 and Figure 8. Equation (5) is obtained from the exponential graph in Figure 8,

$$
f_{0}=1167.4 e^{-0.032 d_{n}}
$$

where $d_{n}=$ distance of the $n$-th fret from the bridge. The correlation can also be expressed in the logarithmic form and the equation is given as

$$
f_{0}=-477.7 \ln \left(d_{n}\right)+2077.3
$$

It is found that both exponential and logarithmic equations give similar results. The average deviations from both equations, however, are found to be near 58 $\mathrm{Hz}$ which is considered high. Hence, the results are plotted using the power trendline which gives the Equation (7) below

$$
f_{0}=13267 d_{n}^{-1.037}
$$

Equation (7) proved to give more accurate calculation results compared to the other two mentioned above in which the average deviation from the measured values is only $11.25 \mathrm{~Hz}$. It is further proven by the trendline reliability value of $\mathrm{R}$-squared. The reliability value given by the power trendline is closer to the perfect value 1 , which is shown in Table 6 below. It can be concluded that Equation (7) is best to represent the correlation of fundamental frequency and the distance of the frets from the bridge. The general equation of the correlation can be written as

$$
f_{0}=\alpha d_{n}^{-\beta}
$$

where $\alpha=$ constant with unit $\mathrm{Hz} / \mathrm{m}^{-1}$ and $\beta=$ unit-less constant.

Table 5: Comparison of fret distance from the bridge and fundamental frequency.

\begin{tabular}{cccc}
\hline $\begin{array}{c}\text { Fret } \\
\text { No. }\end{array}$ & $\begin{array}{c}\text { Distance from } \\
\text { previous fret, } \boldsymbol{d} \\
(\mathbf{c m})\end{array}$ & $\begin{array}{c}\text { Distance from } \\
\text { the bridge, } \boldsymbol{d}_{\boldsymbol{n}}\end{array}$ & $\boldsymbol{f}_{\mathbf{0}}, \mathbf{( H z )}$ \\
$\mathbf{( c m})$ & \\
\hline 1 & 0.0 & 65.7 & 176.62 \\
2 & 6.2 & 59.5 & 195.44 \\
3 & 10.4 & 49.1 & 237.47 \\
4 & 4.5 & 44.6 & 262.51 \\
5 & 7.9 & 36.7 & 316.02 \\
6 & 3.9 & 32.8 & 358.21 \\
7 & 3.5 & 29.3 & 398.52 \\
8 & 5.1 & 24.2 & 488.57 \\
9 & 2.1 & 22.1 & 540.28 \\
10 & 3.8 & 18.3 & 662.65 \\
11 & 2.0 & 16.3 & 712.40 \\
12 & 1.9 & 14.4 & 862.62 \\
13 & 2.3 & 12.1 & 1059.50 \\
\hline
\end{tabular}

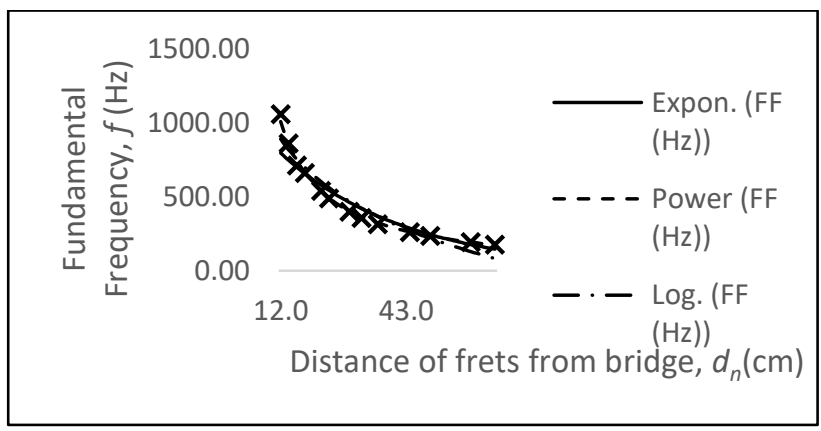

Figure 8: Fundamental frequency of $1^{\text {st }}$ string versus distance of frets from the bridge.

The correlation finding in this study is compared with the result on the sundatang musical instrument (Batahong \& Dayou, 2016). Table 7 shows the correlation equations of sape and sundatang made by acacia and vitex wood. For sundatang, both exponential and logarithmic equations are proved to be fit in determining the fundamental frequency with a small deviation between two types of woods. For sape, the power equation is found to be better in getting the fundamental frequency with the average deviation is much smaller than the exponential and logarithmic equation. 
Table 6: Types of trendline analysis and the R-squared value.

\begin{tabular}{|c|c|c|c|}
\hline $\begin{array}{c}\text { Type of } \\
\text { Trendline }\end{array}$ & Correlation Equation & $\begin{array}{c}\text { Average } \\
\text { Deviation } \\
(\mathbf{H z})\end{array}$ & $\begin{array}{c}\text { R- } \\
\text { squared } \\
\text { value } \\
\text { (perfect } \\
\mathbf{= 1}\end{array}$ \\
\hline Exp & $f_{0}=1167.4 e^{-0.032}$ & 57.09 & 0.9381 \\
\hline $\log$ & $f_{0}=-477.7 \ln (d)+2077.3$ & 58.06 & 0.9255 \\
\hline Power & $f_{0}=13267 d_{n}^{-1.037}$ & 11.25 & 0.9984 \\
\hline
\end{tabular}

Table 7: Comparison of Correlation Equation between sundatang and sape.

\begin{tabular}{ccc}
\hline Instrument & $\begin{array}{c}\text { Correlation } \\
\text { Equation }\end{array}$ & $\begin{array}{c}\text { Average } \\
\text { Deviation } \\
(\mathbf{H z})\end{array}$ \\
\hline $\begin{array}{c}\text { Sundatang } \\
\text { (acacia) }\end{array}$ & $f_{0}=1247 e^{-3.85 d_{n}}$ & 10.73 \\
\hline $\begin{array}{c}\text { Sundatang } \\
\text { (vitex) }\end{array}$ & $f_{0}=-460 \ln \left(d_{n}\right)-161.8$ & 10.80 \\
& $f_{0}=161 e^{-4.26 d_{n}}$ & 13.91 \\
\hline $\begin{array}{c}\text { Sape } \\
\text { (merdang) }\end{array}$ & $f_{0}=-601 \ln \left(d_{n}\right)-278.6$ & 13.65 \\
& $f_{0}=1167.4 e^{-0.032 d_{n}}$ & 57.09 \\
& $f_{0}=-477.7 \ln \left(d_{n}\right)+2077.3$ & 58.06 \\
& $f_{0}=13267 d_{n}^{-1.037}$ & 11.25 \\
&
\end{tabular}

\section{CONCLUSION}

This research initiates the study on sape, a traditional musical instrument in Sarawak. The study is mainly focused on two aspects, the effects of the fret number, and the effects of the fretted string length on the fundamental frequency produced. The result of the study shows that the fundamental frequency produced increased as the fret number increased. The fundamental frequency of each fret can be predicted by using the Fundamental Frequency (FF) equation and Gradient Harmonic Frequency (GHF) equation. On the other hand, although the fundamental frequency of the sound produced is inversely proportional to the length of the fretted strings which is a piece of common knowledge, it is best fitted with the power equation given by $f_{0}=\alpha l_{n}^{-\beta}$ where $f_{0}$ is the fundamental frequency of the fretted string, and $\alpha$ and $\beta$ are constants depending on the fret number, $n$. The findings of this study provide important information on the sound production of sape. It can be used as a guideline for all to understand well the fundamental sound generation due to the effects of the frets. Equations formulated in this study may serve as a standard guideline for the fabrication of the instrument.

\section{ACKNOWLEDGEMENT}

This paper is based on work supported by the University of Technology Sarawak under Grant No 4/2018/01.

\section{REFERENCES}

[1] Yoshikawa, S. (2007). Acoustical classification of woods for string instruments. The Journal of the Acoustical Society of America, 122(1), 568-573.

[2] Yoshikawa, S. (2010). Plucked string instruments in Asia. In The science of string instruments (pp. 173195): Springer.

[3] Yoshikawa, S., \& Waltham, C. (2014). Woods for wooden musical instruments. Paper presented at the Proceeding of ISMA.

[4] Brémaud, I. (2012). Acoustical properties of wood in string instruments soundboards and tuned idiophones: Biological and cultural diversity. The Journal of the Acoustical Society of America, 131(1), 807-818.

[5] Paquier, M., Hendrickx, E., \& Jeannin, R. (2016). Effect of wood on the sound of oboe as simulated by the chanter of a 16-inch French bagpipe. Applied Acoustics, 103, 47-53.

[6] Kusumaningtyas, I., Yordaniansyah, H., \& Purwanto, T. A. (2016). Acoustical properties of petung bamboo for the top plate of guitars. Applied Acoustics, 112, 123-130.

[7] Aditanoyo, T., Prasetiyo, I., \& Putra, I. B. A. (2017). Study on vibro-acoustics characteristics of bamboobased violin. Procedia engineering, 170, 286-292.

[8] Ismail, A., Samad, S. A., Hussain, A., Azhari, C. H., $\&$ Zainal, M. R. M. (2006). Analysis of the Sound of the Kompang for Computer Music Synthesis. Paper presented at the 2006 4th Student Conference on Research and Development.

[9] Batahong, R., \& Dayou, J. (2003). Mathematical Modeling of Sound Frequency Determination of Kulintangan. Paper presented at the The XI Science and Mathematics National Symposium.

[10]Batahong, R., Dayou, J., \& Romut, J. (2014). Traditional Construction Technique of Sundatang. Paper presented at the 12th International Borneo Research Council Conference.

[11]Batahong, R. Y., Dayou, J., Wang, S., \& Lee, J. (2014). Vibrational Properties of sundatang soundboard. Archives of Acoustics, 39.

[12] Batahong, R. Y., \& Dayou, J. (2016). Effect of Frets to Sound Frequency of Sundatang. Jurnal Teknologi, 78(2). 
[13] Ong, C. W. and Dayou, J. 2009. Frequency Characteristic of Sound from Sompoton Musical Instrument. Borneo Science. 25: 71-79.

[14] Wong, T. H., Dayou, J., Ngu M. C. D., Chang, J. H. W. and Liew, W. Y. H. 2013. Clamped Bar Model for Sompoton Vibrator. Archives of Acoustics. 38(3): 425-432.

[15] Wong, T. H., Dayou, J., Ngu M. C. D., Chang, J. H. W. and Liew, W. Y. H. 2013. Analysis of Vibrator for Sompoton Using Cantilever Beam Model. Borneo Science. 32: 13-19.
[16]Fletcher, N. H. and Rossing, T. D. 1998. The Physics of Musical Instruments. New York: Springer-Verlag, 2nd Edition.

[17]Rossing, T. D. 2010. The Science of String Instruments. United States: Springer Science+Business Media, LLC. 